\title{
Sociocultural anthropoecology as an element of human resources management policy in the context of sustainable development.
}

\author{
Larisa Konstantinovna Kruglova* \\ FSBEI HE "Admiral Makarov State University of Maritime and Inland Shipping", Saint-Petersburg, \\ Russia
}

\begin{abstract}
The article examines the heuristic and methodological potential of socio-cultural anthropoecology as an element of human resources management policy in the context of sustainable development. The author defines socio-cultural anthropology ecology as the science of the laws of structure, functioning and development of the ecosystem "man - nature society - culture". The article shows that the development of socio-cultural anthropoecology as a scientific discipline makes it possible to get new knowledge in such spheres as general principles of human interaction with the living environment and its individual components; favorable and unfavorable living conditions (natural, social, cultural) typology of personality, the criterion of which construction is the nature of the interaction of the individual with the environment of life. The article concludes that the institutionalization of socio-cultural anthropoecology and its development as a scientific and educational discipline are necessary for strengthen of theoretical base and increasing of effectiveness of human resource management policy in the context of sustainable development
\end{abstract}

\section{Introduction}

Solving the problem of sustainable development is of crucial importance for humanity. The legitimacy of this kind of reasoning has its grounds and follows from the understanding of sustainable development as such a development of mankind in which "meeting the needs of the present does not undermine the ability of future generations to meet their own needs" [1]. Accordingly, a negative result in solving the problem of sustainable development, i.e. the exhaustion of the possibilities of satisfying the needs of future generations, in reality, will appear not as some distressing failure, the lessons of which can be taken into account in the future, but as the death of humanity, as a sentence carried out.

The main difficulty and at the same time the main opportunity for a successful solution to the problem of sustainable development is the most powerful and at the same time inexhaustible resource that can be used for these purposes is human resources, i.e. the salvation of man as a species depends entirely on the man himself.

\footnotetext{
"Corresponding author: 1kkruglova@gmail.com
} 
It is gratifying to note that this idea is slowly but steadily acquiring the status of the dominant one in the modern public consciousness. She received a convincing argument in the work of J. Simon "Inexhaustible resource", where the author confidently declares that "the primordial and inexhaustible resources of the earth are the people who are skillful, knowledgeable, full of animation and hope, who strain their strength and imagination to make life better not only for themselves, but also for society as a whole. " [2, p.28]

It is characteristic that the idea of the need for a "human revolution" to solve environmental problems was presented by Aurelio Peccei as the main result of his activities and the activities of the Club of Rome, he was one of the founders whereof [3]. It is quite significant that in the anniversary report of the Club of Rome, timed to coincide with its fiftieth anniversary, the concept of "New Enlightenment" occupies a central place, ie. the problem of a radical change in the spiritual component of what is designated by the concept of "human resource" [4, 5].

The decisive importance of anthropological problems for determining the ways of development of earthly civilization is expressively emphasized in the title of the theme of the XXIV World Philosophical Congress - "Learning to be human" (Beijing, August 13-20, 2018 [5-8].

At the same time, it should be noted that the idea of the inexhaustibility of the human resource is opposed by the idea of an anthropological crisis as one of the global problems of our time [9]. However, it seems that the opposition of these ideas not only does not deny the importance of human resources for determining the fate of mankind, but, on the contrary, tragically emphasizes, sets off, reveals this meaning, since we are talking about the possible exhaustion of the main resource that a person has in resolving the issue " to be or not to be".

But as soon as this is so, and the main life-supporting resource of mankind is contained in itself, then inevitably the problem of managing this resource arises. "The most common management functions are: maintenance and optimization of system characteristics, a conscious impact on internal and external (in relation to the system) processes [10].

The concept of "management" is now accepted to associate with the concept of "management policy". It should be noted that traditionally the concept of politics was used mainly in relation to the sphere of interaction of various social groups and states. At the same time, it was interpreted and is being interpreted in such a different way that, for example, in the publication "New Philosophical Encyclopedia" on the word "politics" there are three articles by different authors (G.Yu. Semygin, A.P. Ogurtsov, T.A. Alekseeva), and in each of them the author's position is supplemented by a broad overview and analysis of other approaches to the definition of policy. Using the presented in these articles and, in particular, in the article by G.Yu. Semigin [11], materials, and taking into account the current trend of an expanded understanding of the phenomenon of politics, it can be stated that the policy of human resource management includes the following points:

- determination of the goals and directions of human resource development in accordance with the interests of subjects of different levels (humanity, country, region, corporation, individual),

- the choice of means to achieve the set goals,

- organization and implementation of practical actions to achieve the set goals.

It is quite obvious that the successful implementation of human resource management policies in the context of sustainable development, which, as shown earlier, is of crucial importance for humanity as a whole, and for an individual human community, and for individual organizations, is possible only on a solid scientific basis.

The result of realizing this need can be considered the formation and development of such a scientific and educational discipline as "Human Resource Management". However, as it turns out, this discipline is currently strictly localized to the sphere of economic 
sciences, as evidenced, for example, by the composition of the team of authors of a very solid textbook for students of higher educational institutions "Human Resource Management [12]. It was prepared by the staff of the Department of Labor Economics and Labor Resources of the St. Petersburg State University of Economics and members of the editorial board of the journal Creative Economy. The team of authors (20 people) includes only doctors and candidates of economic sciences. To this we can add that the textbook is intended only for students of economic specialties.

Meanwhile, it is quite obvious that the scientific basis of human resource management policy, in view of the complexity that the human phenomenon is, should include knowledge in the field of philosophy, anthropology in all its varieties, sociology, cultural studies, psychology and other humanities. The diversity of sciences and disciplines related to the field of human studies suggests that some kind of integrative discipline is needed that would ensure the meaningful unity of this diversity and would contribute to the translation of the language of the human sciences into the language of practice.

It seems that sociocultural anthropoecology can act as such an integrative, and at the same time innovative discipline. The starting point of its construction is a broader understanding of ecology, proceeding from the initial idea of it as a science of the interaction of organisms with the environment, which is directly related to the etymological meaning of the word - eikos - house. Here it is important to emphasize the meaning of both meaning-forming words - interaction and environment (home, eikos). At the same time, if for an animal it is the environment, the home is nature, then for a person the environment and the home is not only nature, but also the society and culture created by it. Based on this, we can conclude that sociocultural anthropoecology is designed to study the principles and laws of human interaction with the environment of his life, including nature, society and culture.

In accordance with the above-mentioned, the purpose of the presented article is to identify the heuristic, methodological and practical potential of sociocultural anthropoecology as an element of human resource management policy in the context of sustainable development.

The tasks, the solution of which is necessary to achieve this goal, are:

- to define the subject of sociocultural anthropoecology;

- to identify the main points of the content of sociocultural anthropoecology as a scientific and academic discipline and the possibility of its practical use as an element of human resource management policy in the context of sustainable development.

\section{Materials and Methods}

The content of the presented article is based on the author's works on the innovative discipline "Sociocultural Anthropoecology ", which does not yet have a corresponding place in scientific discourse, educational process and practical activity [13-15].

In addition, the work used the works of domestic and foreign scientists on ecology [1620], social ecology [21], ecological history [22], human ecology [23,24], ecological aesthetics [29,30], cultural ecology [ 26-28], human resource management [12], materials of the international commission on the environment, reports of the Club of Rome [1,4], materials of the XXIV World Congress of Philosophy [5-8].

The solution of the problems posed in this work required the use of a number of methods of theoretical research. Among them:

- holistic, the need for which is due to the fact that the subject of sociocultural anthropoecology is the multicomponent integrity "man-nature-society-culture". 
- systemic - allowing to consider a person, nature, society and culture as a single ecosystem, to determine the type of this system, its systemic (emergent) properties, the laws of its structure, functioning and development.

- hermeneutic, which is associated with the holistic method by the relationship of complementarity, since it allows to solve the problem of the hermeneutic circle, which is that the whole cannot be cognized without knowing the individual parts, and the individual parts cannot be cognized without knowing the whole; from the standpoint of hermeneutics, this circle can be broken with the help of intuition, imagination, thanks to which it becomes possible to "see" the whole image of the object under study.

- synergistic - allowing to determine the nature and specifics of self-organization processes in the ecosystem "man-nature-society-culture" [30].

In addition to the methods of the theoretical level of research, the work contains references to the results of empirical research, which are found in the above-mentioned works on ecology, social ecology, and human ecology.

\section{Results and discussion}

Currently, environmental knowledge is represented by a number of sciences and disciplines. This is, first of all, ecology as a biological science about the relationship of living organisms and their habitat. The development of this science, the founder of which is the German zoologist Ernst Haeckel (1834-1919), led to the understanding that man and his environment are also a single ecosystem. Associated with this is the modern interpretation of ecology as a science, the subject of which is the relationship between human society and its environment. In order to distinguish it from ecology as a kind of biological science, some researchers propose to define this branch of ecological science as social ecology [22].

In addition, in the course of the development of environmental science, it became necessary to single out another special environmental discipline - human ecology.

However, it seems that both in modern ecology and in human ecology the content of the concept "environment" is unjustifiably limited.

So, V.N. Movchan sees the task of the discipline "human ecology" in focusing on two interrelated processes: adaptive changes in the human population under the influence of natural and technogenic limiting factors and changes in natural complexes experiencing anthropogenic impact [21, p. 12-13].

Another author, B.B. Prokhorov, expands the subject field of human ecology and includes in it the study of the impact on the population of not only natural, but also "... social, household, production factors, including culture, customs, religion" [24, p. 18]. However, here there is a limitation of a different kind, since we are not talking about interaction, but only about the impact on the population of social and cultural factors, that is, a person appears as a passive element of the ecosystem.

The most widespread understanding of the subject of human ecology is given, for example, by the journal Human Ecology, published in Arkhangelsk. It is intended to publish the results of scientific research in the field of medical, biological and technical sciences and, I must say, basically corresponds to the designated boundaries of the subject field of human ecology. So, in all issues of the magazine for 2021, it was possible to find only one article, the content of which shows that, in addition to natural factors, social factors of the environment also act on a person, in particular, news of terrorist acts. [25]

As for the awareness of the role of culture as an element of the human life environment, it, as expected, took place and is happening among the humanities, who actively supported the idea of "ecology of culture" put forward by Academician D.S. Likhachev. However, it must be admitted that in this area there was and still is a kind of limitation, since the 
ecology of culture is understood mainly as activities for the preservation of cultural heritage. [25.26]

It must be said that this is also characteristic of ecology as such, with which, in both everyday life and in scientific consciousness, the idea of environmental protection is associated, first of all.

Thus, it can be stated that not only none of the above environmental disciplines (ecology, social ecology, human ecology, cultural ecology), but all of them in total, do not cover the problem field, the boundaries of which are indicated by the posing of the question of human interaction with its environment.

First of all, it is necessary to take into account that a person's living environment, his home - eikos - is not only nature, but also society and culture. Man is incapable of living outside nature, but he is incapable of living outside society and culture to the same extent. As a result, man, nature, society and culture become integral elements of a single ecosystem.

It seems that the laws of the structure, functioning and development of this ecosystem should become the subject of study in a special ecological discipline - sociocultural anthropoecology.

Based on the ideas about the structure of the human living environment, sociocultural anthropoecology can be divided into several sections:

- social ecology - the science of the interaction of society and, therefore, a person and his environment

- social anthropoecology - the science of the interaction of man and society

- cultural anthropoecology - the science of the interaction of man and culture.

Each of the components of the human habitat - nature, society-culture - can be structured at least into three levels: mega-environment, macro-environment, microenvironment. Their specificity also presupposes the specificity of human behavior within the framework of each of them.

If we consider the system "man - nature - society - culture" from the point of view of synergetics, then one should pay attention to the fact that in this system a person, as an element of the system, has the greatest synergistic potential, since he is the bearer of the properties of all other elements of the system - natural, social and cultural.

Pursuant thereto, the primary task of sociocultural anthropoecology, as a unified scientific discipline, is to search for some general principles of human interaction with the environment.

It seems that the most important of these principles is the worldview principle of harmony, which allows a person to evaluate all elements of the environment and build their behavior in terms of the presence of two necessary features: diversity and unity. There is no variety - monotony is obtained, there is no unity - a cacophony is obtained.

The speculative principle of harmony should be supplemented with a principle that would indicate the energy source of human activity. Such, undoubtedly, is the principle of love - to oneself, to another, to one's native land, to nature, to humanity.

And, finally, the principle of harmony, which sets the angle of speculation, and the soulemotional principle of love, apparently, need to be supplemented with the principle of a practically effective relationship to the environment, that is, the principle of creative action. Its meaning is expressed in the wisdom that Voltaire's Candide came to after his long and painful wanderings: "We will cultivate our garden."

All these principles are deeply rooted in the history of culture and have already found their place not only in philosophical, but also in scientific discourse [14,15].

The basic principles of human interaction with the environment constitute the core of the methodological base of sociocultural anthropoecology. On this basis, using a complex of knowledge about man, nature, society and culture, it becomes possible to solve one of 
the most important tasks of sociocultural anthropoecology as a scientific and educational discipline - the formation of a body of knowledge about favorable and unfavorable conditions of the natural and sociocultural environment. It should be noted that at present we have sufficiently large data on the favorable and unfavorable conditions of the natural environment for human life, the social and cultural environment in this regard is still poorly studied. Meanwhile, both at the level of scientific consciousness and at the level of common sense, there is a clear understanding that, for example, an aggressive social or cultural environment is just as destructive for a person as an aggressive natural environment. In this regard, one cannot but recall the well-known statement "the environment has stuck". And, on the contrary, a favorable socio-cultural environment is as healing for a person as fresh air, clean water, and the light of the sun.

It is quite obvious that the formation of a block of knowledge about favorable and unfavorable conditions not only of the natural, but also of the socio-cultural environment of a person, considered at the mega - macro - and micro levels, is of particular importance for the development and implementation of human resource management policies in the context of sustainable development, since only on this basis it is possible to determine indicators of the state of the environment and create an appropriate regulatory framework. At present, such indicators have been developed only for the natural and man-made component of the human environment. At the same time, the technogenic component means basically the same natural one, that is, the state of water, air, etc. - only experienced by a person. As for the social and cultural components of the human life environment, here we have to admit that there is no clear system of indicators regarding them, and the existing laws and regulations, as a rule, are not implemented. For example, the Urban Development Complex of Russia in 2004. In the first paragraph of his first article "Principles of sustainable development of the territory", as a regulatory requirement, it is stated that "in new settlements or quarters, a humane number of storeys of residential buildings (no higher than 5 floors) is being created" [32]. Instead of fulfilling this requirement, we see in megalopolises the construction of so-called "human beings", which, both in size and in architecture, have nothing to do with anthropomorphism and humanity.

This problem is of global importance. In particular, it was discussed at the XXIV World Philosophical Congress. So, at the section "Environmental Philosophy" they discussed the destructive influence of high-rise architecture on people, the need to take into account the principles of "cooperation with the sun", "respect for the inhabitant", "respect for the place" in urban planning $[6, \mathrm{p} .18]$.

It is quite obvious that these and other principles, united by the concept of "humanism", should form the basis for the development of indicators of the state of the human environment at all levels - from the global one to the level of a separate organization, a separate settlement, and finally, a separate house.

Meanwhile, from the analysis of the content of training courses in the university discipline "Human Resource Management" we can conclude that they do not pose the problem of favorable and unfavorable conditions in the socio-cultural environment and, accordingly, are not solved. One of the reasons for this is the obsession of the authors of these courses on economic issues and underestimation, not to say neglect, of other social and humanitarian sciences. Suffice it to say that, for example, in the "Conclusion" of the already mentioned textbook "Human Resource Management", under the editorship of I.A. Maksimtsev, N.A. Gorelov [12] named "the formation of new economic thinking" as the main goal of human resource management.

The implementation of the methodological and heuristic potential of sociocultural anthropoecology allows us to solve another problem that is directly related to the policy of human resource management. This is the problem of constructing a personality typology [32]. In the context of sociocultural anthroecology, the main criterion for typologization is 
the nature of the person's interaction with all the components of his living environment nature, society and culture. This criterion, first of all, makes it possible to single out the main types of personality, the vectors of interaction of which with the environment are directly opposite. They are "creator", "constructor" - on the one hand, and "predator", "destroyer" - on the other. In addition, within the framework of this typology, intermediate personality types can be distinguished: among the positive ones - "doctor", "orderly", among the negative ones - "slob." environment - natural, social and cultural. A "slob" is a type of personality whose activity is not directly aimed at destroying the environment, but leads to its clogging and, accordingly, degradation.

The use of this kind of typology in human resource management policy can be expressed in the form of the development and implementation of programs for encouraging and stimulating individuals of a positive series and neutralizing the undesirable consequences of actions of individuals of a negative series.

The possibilities of realizing the heuristic and methodological potential of sociocultural anthropoecology, as a scientific and academic discipline, are systematically presented in a number of works by the author of this article [13-15]. However, the ideas of these works and numerous articles published in various collections have not yet evoked either positive or critical comments, that is, they have remained unnoticed. In accordance with this, it can be stated that sociocultural anthropoecology has not yet developed as a scientific and academic discipline, but does not even exist at the level of discussions.

However, given the powerful heuristic, methodological and, most importantly, the practical potential of sociocultural anthropoecology as a scientific and academic discipline, there is every reason to believe that its institutionalization, development and use in practice, in particular, in the development and implementation of human resource management policies, this is a matter of the near future.

\section{Conclusions}

1. Sociocultural anthropoecology as a science about the laws of the structure, functioning and development of the ecosystem "man-nature-society-culture" has an innovative character, since on its basis it is possible to expand the volume of knowledge about man and the ways of his interaction with the environment.

2. As an innovative discipline, sociocultural anthropoecology can perform an integrative function in relation to the entire body of environmental, socio-economic and humanitarian sciences, which are currently part of the theoretical framework of human resource management policy.

3. Institutionalization and development of socio-cultural anthropoecology as an educational and scientific discipline is necessary to strengthen the theoretical base and increase the effectiveness of human resource management policy in the context of sustainable development at all levels of its development and implementation: from the global to the level of an individual organization and settlement.

\section{References}

1. S.A. Evteeva and R.A. Pereleta, Report of the International Commission on Environment and Development (ICED), translated from English 376 (1989)

2. J. Simon, An inexhaustible resource, 797 (2009) 797 p.

3. A. Peccei, Human qualities, 302 (1980)

4. Come On! Capitalism, myopia, population and planet destruction, https://www.researchgate.net 
5. D. I. Dubrovsky, Problems of Philosophy, 12, 77 (2018)

6. A. N. Chumakov, A. D. Korolev, Problems of Philosophy, 3, 15 (2019)

7. M. T. Stepanyants, Problems of Philosophy, 3, 22 (2019)

8. B. I.Pruzhinin, T. G. Shchedrina, Problems of Philosophy, 3, 33 (2019)

9. D. I. Dubrovsky and S. M. Klimova, Global Future: Anthropological Crisis, Convergent Technologies, Transhumanist Projects (2014),

10. I. A. Vasilenko Management, New Philosophical Encyclopedia, 4, 144 (2010)

11. G. Yu. Semigin, Politics, New Philosophical Encyclopedia, 3, 269 (2010)

12. I. A. Maksimtsev, N. A. Gorelov, Human resource management, 467 (2019)

13. L. K. Kruglova, Sociocultural anthropoecology, 75 (2000)

14. L. K. Kruglova, Man-Nature-Society-Culture: Sociocultural Anthropoecology, 120 (2013)

15. L. K. Kruglova, SELECTED WORKS. Anthropological principle in cultural studies: theory and practice. Section II, Sociocultural Anthropoecology, 39 (2018)

16. T. A. Akimova, V. V. Khaskin, Ecology, 495 (2007)

17. K. S. Losev, Myths and misconceptions in economics, 224 (2011)

18. A. A. Muzalevsky, Ecology. Tutorial, 664 (2008)

19. A. A. Popov, Ecology of the era of globalization of nature management, 600 (2009)

20. A. F. Bugaev, Global Ecology: Conceptual Foundations, 496 (2010)

21. E. V. Girusov, Fundamentals of Social Ecology, 168 (1998)

22. Man and nature: ecological history, 349 (2008

23. V. N. Movchan, Human ecology, 292 (2006)

24. B. B. Prokhorov, Human ecology, 320 (2007)

25. O. A. Plyushkevich, R. V. Ivanov, I. A. Zhuravleva, A. V. Zavyalov, Human Ecology, 8, 42 (2021)

26. D. S. Likhachev, Selected works on Russian and world culture. 2nd ed, 485 (2015)

27. D. S. Likhachev, Selected works on Russian and world culture. 2nd ed, 21 (2015)

28. E. N. Ustyugova, Bulletin of St. Petersburg University, 3, 64

29. V. V. Prozersky, Bulletin of St. Petersburg University, 3, 22

30. T. A. Akindinova, Bulletin of St. Petersburg University, 3, 58

31. L. K. Kruglova, Man and culture, 60 (2017)

32. Urban Planning Code of the Russian Federation of December 29, 2004 N 190-FZ (2021) http://www.consultant.ru

33. L. K. Kruglova, SELECTED WORKS. Anthropological principle in cultural studies: theory and practice. Section II, Sociocultural Anthropoecology, 152 (2018) 